\title{
THE INTEGRATED 3D SURVEY FOR PLANNED CONSERVATION: THE FORMER CHURCH AND CONVENT OF SANT'AGOSTINO IN BERGAMO
}

\author{
Alessio Cardaci ${ }^{1 *}$, Giulio Mirabella Roberti ${ }^{1}$, Antonella Versaci ${ }^{2}$ \\ ${ }^{1}$ Dept of Engineering and Applied Sciences, University of Bergamo, Bergamo, Italy \\ (alessio.cardaci, giulio.mirabella)@unibg.it \\ ${ }^{2}$ Faculty of Engineering and Architecture, University of Enna "Kore”, Enna, Italy \\ antonella.versaci@unikore.it
}

\section{Commission II}

KEY WORDS: planned conservation, restoration project, cultural heritage monitoring, 3D integrated survey

\begin{abstract}
:
Time effects and human offenses threaten cultural heritage. The constant observation and periodic maintenance activities are the most suitable safeguarding solution: they can limit risk situations and facilitate interventions. Today, planned conservation is thus the best pattern to preserve the monuments as focused on small preventive restoration: actions organized and structured according to steady and regular monitoring. The preliminary survey, the interpretation of metric and material data and the subsequent verification of the evolution of instability and degradation phenomena based on a comparison with previous information, is a long and expensive activity if carried out by traditional systems. Otherwise, 3D laser scanning and image-based reconstruction methodologies - if properly applied within optimized operational practices - can allow both the systematic control of assets' conditions and the evaluation of their health status and decay problems in a short time and with lower costs. This paper intends to show the validity of such an innovative methodology through a case study applied to the former church and convent of Sant'Agostino (St. Augustine) in Bergamo.
\end{abstract}

\section{INTRODUCTION}

The town of Bergamo is known for its imposing city walls that enclose the oldest part of the town and were recently added to UNESCO's World Heritage List (Bonadei et al., 2016). They were built by the Republic of Venice from the 31 July 1561 . under the will and the direction of Count Sforza Pallavicino, Governor of the Serenissima - and completed in 1588. They absolved more a political than a military function, as they were essentially used for defensive and not for attacking purposes, due to their limitation to the upper (alta) town, the seat of the government and the administration of the region, relatively small in size and then unable to accommodate large contingencies.

The fortifications were conceived to redesign the city's face and convey the image of Venice in a historical period in which following the discovery of the Americas - the Mediterranean Sea was losing its central role and the domain of the Serenissima was on the way of an almost inevitable decline (Zanella 1990, Colmuto \& Zanella 2011). Consequently, they were planned to be an impressive architectural structure, which also incorporated some existing buildings that in most traits influenced their constructive genesis, such as the church and the monastery of the Eremitani di Sant'Agostino

The religious complex, differently from that of the Domenicani for example, was not demolished because Augustinian fathers paid a large sum of money to enclose it in a more extended perimeter (Cristini 2012). Its eventual overthrow o was strongly opposed also by the local administration (Bravi 2014). However, according to the architect Elia Fornoni, the modification of the first project (which foresaw the walls built against the fortress of San Marco) was mostly motivated by economic advantage linked to the construction. In fact, the original route, as well as to create an easily helpless area, would have required breaking down much of the rocky relief of the hill of Sant'Agostino: a very expensive and long work (Figure 1).
In any case, the convent was spared and three outer bastions were built - San Michele, Sant'Agostino, and the adjoining bastion called del Pallone - and arranged in a double tenaille defensive configuration. Realized towards 1575 , the namesake gate giving access to the city from East, majestic and imposing in its forms, was enriched with the construction on its axis of a fountain, based on the same tripartite scheme.

Today, the monastic complex of Sant'Agostino is the highest expression of late Gothic architecture still existing in the city of Bergamo. The historical sources trace its construction back to 1290 (Schiavini \& Trezzi 2007) on a hill in the direction of Venice and outside the medieval city, where there was a small chapel dedicated to Saints Philip and James.

The actual church consecrated in 1347 has a single nave, with transversal arches sustaining the roof, originally shown no lateral chapels and an extended podiolo (a raised structure, more properly defined iconostasis, which separated the choro, destined to the friars and priests from the hall of the faithful). The first altars were collocated along the nave while in the nearby paving areas started to be placed the burials of the nobles of the city.

The possibility offered to aristocratic families to have their own tabernacle inside the sacred space (both for the burial and for the Mass) is at the base of the transformation of the plexus in the $16^{\text {th }}$ and $17^{\text {th }}$ centuries. The demolition of the podiolo and the construction of the new lateral chapels, in an intent of uniform style and decoration, changed the segmented medieval space into a unitary environment.

The convent is described in the $18^{\text {th }}$ century as a place of prayer, study, rich in art and beauty (Petrò, 2011). However, this did not prevent the transformation, after the suppression of religious orders in northern Italy in 1797 of the great convent, which became barracks for the several armies that succeeded in the occupation of the city, from the French to the Austrian and finally to the Italian army until 1966. The church was used at the beginning as a riding school, but around 1880 was also 


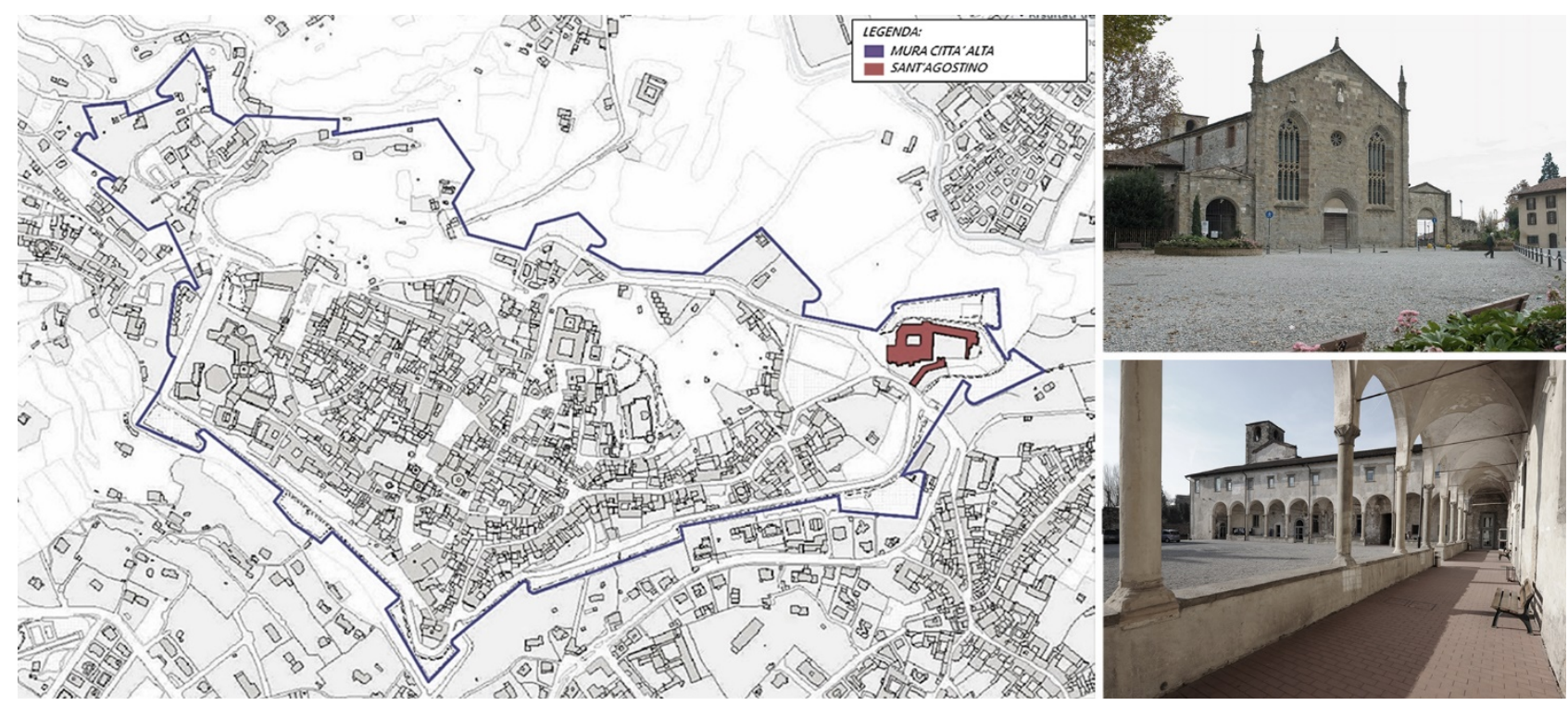

Figure 1. On the left, the layout of the Venetian city walls and the former convent. On the right, from top to bottom, the great cloister of the monastery and the façade of the church.

subdivided in two levels by a wooden floor supported in the middle by a double row of columns, the ground floor becoming a storehouse and the upper floor archives. (Figure 2,3).

In the second half of the $20^{\text {th }}$ century, the debate began for the conservation of the monument but it will be only in the $21^{\text {st }}$ century that work for its restoration and its adaptive reuse starts. Since 2001, the Humanities campus of the University of Bergamo is located in the monastic cloisters, re-enacting through scientific education the intellectual vivacity that was typical of the place. On 21 September 2016, with the inauguration of the assembly hall of the University of Bergamo in the ancient church of Sant'Agostino, finally given back to the city, a first significant step in the process of walls conservation and enhancement was accomplished (Mirabella Roberti 2017). Launched in 2006 and coordinated by the architects Amedeo Bellini and Marcello Sita, the restoration project undertaken a series of actions for the functional and technological retrofitting of former sacred space, redesigned as a new place for cultural events (Bellini 2015).

The numerous construction sites which since then succeeded, have concerned: safety measures on the plastered and painted surfaces (April 2007-May 2008), two archaeological excavation campaigns (the first started in July 2007 - the second in October 2010), the consolidation of the facade and the installation of a new roof (May 2010 - June 2011); and, finally, the realization of the Aula Magna (equipped stage with retractable screen, contrail room for simultaneous translation) and the plant adjustment design (controlled temperature and humidity) for the protection of wall paintings (July 2014-September 2015).

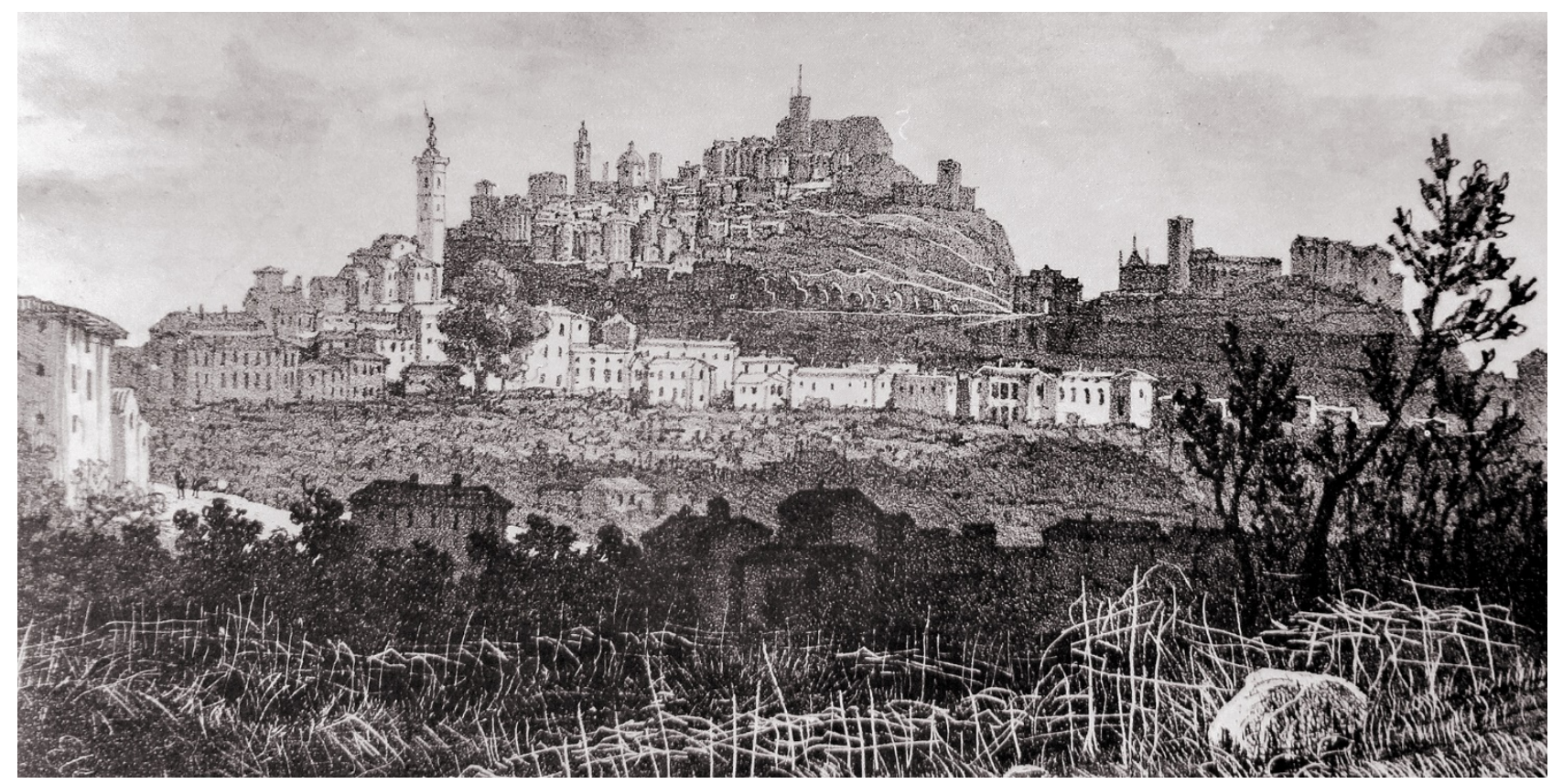

Figure 2. The complex of Sant'Agostino: eastern view from the lower city, 1852 (from the album "Natural and monumental curiosities of Lombardy drawing by Giuseppe Elena" printed by lithography of Corbetta, Milan). 
Today, the task of the University of Bergamo is to preserve a heritage from the past that must be delivered to future generations. Simultaneously with restoration activities, the University has therefore planned a program of metric surveys and diagnostic analysis aimed at both the documentation of the interventions carried out - in a dynamic and continuous vision of what Italians call cantiere della conoscenza and a qualitative verification of planning intentions - and the monitoring of its state of conservation to prevent future decay processes.

For this delicate task, integrated survey procedures have therefore been studied and implemented, which have to be completed with appropriate diagnostic investigations, in order to obtain an overall knowledge of the building organism. This would be synthesized in relational databases, able to locate all the information related to the building, and to manage the infinite interrelations in time, updating them continuously and preserving their temporal stratification (Musso, 2017).

\section{THE FORMER CHURCH OF SANT'AGOSTINO BEFORE, DURING AND AFTER THE RESTORATION}

The first survey campaign was carried out before the beginning of the restoration works in order to record the metrical and
The preliminary investigation, the correct interpretation of metric and material data and the subsequent verification of the evolution of instability and degradation phenomena is a long and costly activity if poorly planned and carried out by sectors with the traditional diagnostic and measurement systems.

The use of 3D technologies, both with active and passive sensors also installed on small drones, if properly and consciously applied within optimized operational practices, can allow the systematic control of the conditions of the architectural property, the assessment of its health status and the causes of decay, in a shorter time and with lower costs. Therefore, an evaluation is possible through the critical analysis of data and images recorded at different times and classified in a web database.

The critical aspects of the church of Sant'Agostino mainly concern the fragility of the cycles of frescoes that enrich the walls and the painted clay tiles that adorn the soffit of the ceiling. Any change in the humidity in the walls and/or movements of the structure can, in fact, generate the detachment of the plaster and damages of the decorated elements. The constant monitoring of both micro-cracks and the possible appearance of waterways in the walls is, therefore, a good practice, if not necessary, for the conservation of the artistic value of the monument. Even if no alarm has come out today, it is still important to be aware of the

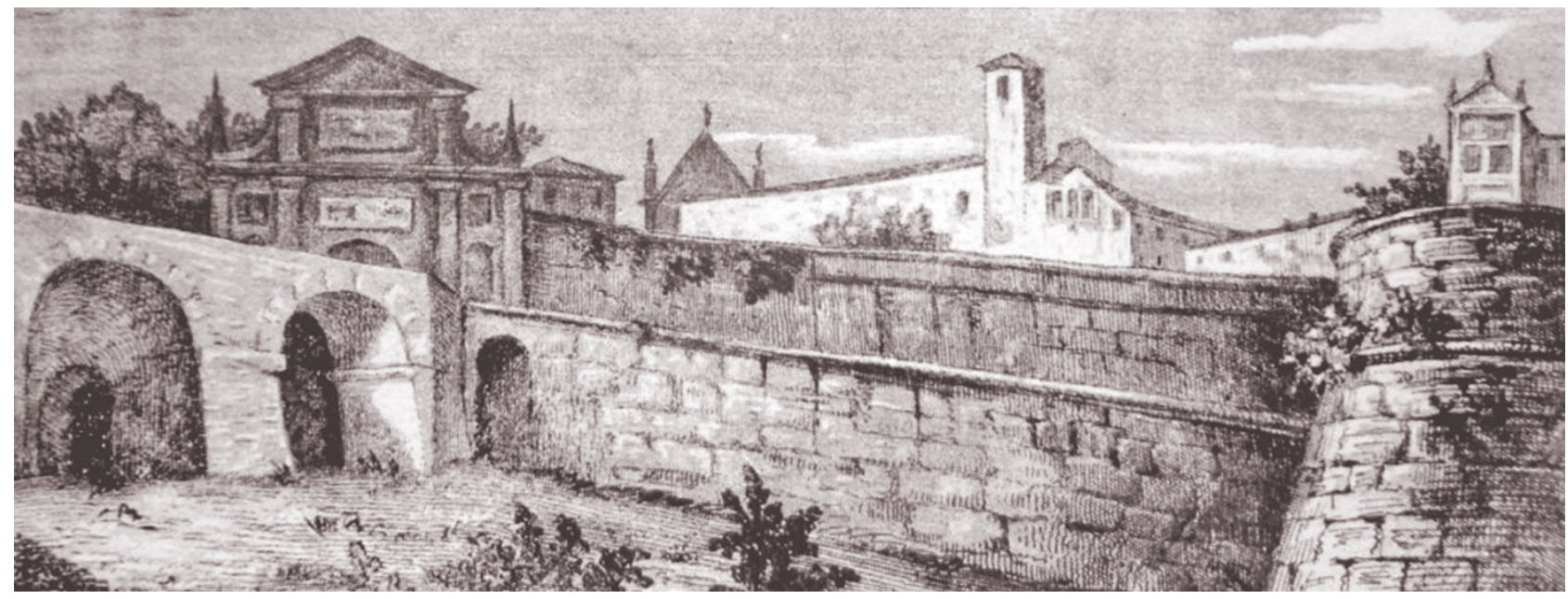

Figure 3. The complex of Sant'Agostino: southern view from under the walls of the Baluardo di Sant'Agostino, 1860 (detail from the lithograph printed by the publisher Vallardi, "Sant'Alessandro, protector of the city of Bergamo").

material status of the building; during the works further investigations became necessary to integrate the documentation related to some particular processes.

The second acquisitions phase was carried out at the end of the construction site to obtain an 'As-Built' documentation describing the architecture after restoration work and including the changes occurred during the site phase and not foreseen in the preliminary design.

The third phase of measurement and the diagnostic investigations is still ongoing; it is a series of surveys that will be carried out at a distance of ten years aimed at the comparison with previous information.

The alteration actions are linked to the effects of time: the consequent ageing of the apparatuses, both architectural and decorative, constantly threatens this precious cultural heritage. Constant visual observation and periodic maintenance activities are the most suitable safeguard solutions because they are able to limit risk situations and facilitate interventions.

Actually, a prevention program, implemented with small actions organized and structured over the years according to constant and regular monitoring, is today the best way to preserve the monuments (Della Torre, 2003). existing situation with a clear and precise overall picture (Battini \& Vecchiattini, 2018). The comparison of the existing condition with the future will indicate, in fact, the tendency in the coming decades and consequently ensure the opportunity to intervene before irreparable damage occurs.

The first evaluations, which were made possible after the analyses of data gathered before the beginning of the construction site and the end of the works, for example, highlighted the presence of moisture in the air of one of the chapels. Even if not imputable to the restoration work, the meteoric water collected on the pavement of the first floor of the minor cloister during the construction site, leaked in part of the wall masonry of the church, soaking it. The waterproofing of the external surfaces has solved the problem of infiltration but not the drying of the wall. It is, therefore, necessary to verify, in the coming years, the reduction of the extent and intensity of the area affected by the phenomenon.

In addition, the heavy transformations of the church following the breaking of important wall sections for the construction of the chapels has generated an important crack pattern that tells the story of stress and tensions undertaken by the structure. The strong inclination of some of the walls and the strong deformation 
of the reinforcing elements of the central spans, provide a series of clues that must be interpreted and monitored in order to appreciate the movements of the structures and the evolution that these can have over the years. Local deformations in some parts of the roof can, in fact, compromise the stability of the tiles and break them.

Here is, therefore, the need for accurate metric knowledge of the entire building system in order to avoid future risky situations.

\section{THE INTEGRATED SURVEY AND THE DATA SHARING PLATFORM}

The integrated survey, if accurate and well executed, is today the most suitable method to obtain a reliable basic reference for the knowledge, the understanding of the construction history and the representation of the aging processes of a building. The constructive anomalies, the irregularities, the decay phenomena over time are the signals that the building transmits to a careful observer and that, to be understood, require, in addition to specific technical skills, extreme caution and a great sensitivity. The deep knowledge of a building and the necessary preliminary anamnesis for the elaboration of a 'credible' and effective restoration project, although strictly linked to the critical skills of the designer, nowadays benefit from the advancement of new techniques and new technologies in order to deduce the most appropriate project choices (Dezzi Bardeschi, 2017).

Moreover, the opportunities offered by the recent software, able to interface with each other in $3 \mathrm{D}$ platforms, have allowed managing in a single virtual model all the metric and material information of the church.

\subsection{The 3D laser scanning survey}

The 3D laser scanning acquisitions provided the geometric structure, according to assumptions and characteristics of high reliability, for the superimposition of the photogrammetric models. They concerned the church, both inside - before and after the execution of the works - and the façade, at the end of the works. The stations have been chosen in order to guarantee a high overlap of the point clouds and to limit the shaded areas. The purpose of the acquisitions is, as previously announced, linked to the monitoring of the movement of structures over time and to the control of any deformations that may arise in future years. Therefore, it was necessary to obtain a very dense point cloud (on average, one point every $3 \mathrm{~mm}$ with an accuracy of $\pm 1.5 \mathrm{~mm}$ ), geo-referenced on the basis of some topographic landmarks irreversibly fixed to the walls for future repositioning.

The first measurement campaign was carried out in July 2015 through the implementation of scans aligned to each chapel, along the longitudinal axis of the church. The not optimal lighting conditions (an uncontrolled mixture of sunlight and incandescent lights) partially compromised the colour quality of point clouds, nevertheless enabling a first 'recording' of the building's state of conservation (Figure. 4).

The second campaign, conducted approximately six months after the first, was carried out in March 2016 after the end of restoration works and with the aula magna was already operative. Scans were conducted within one day in a more rigorous way than previous, both because higher in number (in addition to those along the longitudinal axis, other acquisitions were taken frontally to each chapel) and because taken in a constant and controlled light environment, now assured by the new lighting system (Figure. 5).

This activity has allowed responding to the serious concerns raised by the heavy winter's rains that it was feared could determine the deterioration of areas affected by humidity caused by earlier leaks in walls, especially those frescoed.

The comparison between the data obtained from the first and second campaign, supplemented by hygrometric and thermographic surveys has allowed, for example, to verify the correct execution of the waterproofing works, especially on the left side of the aisle adjacent to the minor cloister.

Beyond these checks, however, the information obtained on the whole complex and interested walls, adding to the already owned historical, material-constructive and diagnostics data, made it possible to implement the structured informatics platform for the future acquisitions.

\subsection{The close-range photogrammetry}

Digital photogrammetry, integrated with the 3D laser scanner acquisitions, has completed the global model. The radiometric and colour information is, in fact, an indispensable component for the correct analysis of material alterations. Pictures were

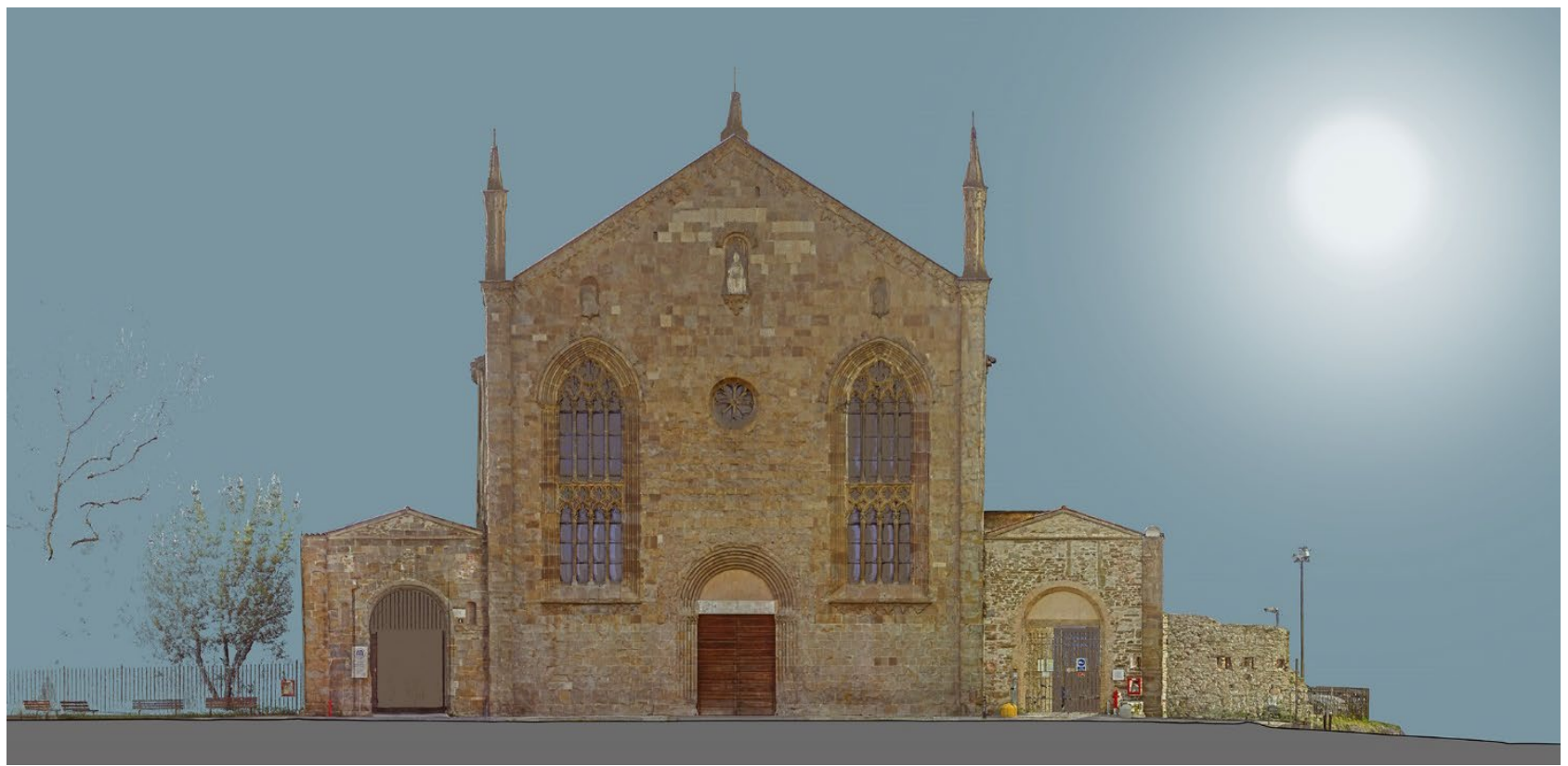

Figure 4. The façade of the church of Sant'Agostino after the restoration: the orthographic projection of the points cloud. 
taken both inside and outside (with different environmental and lighting conditions), both from land and air (with sets of images with different characteristics); they have led to choose the best models according to the needs of the moment (Pepe et al, 2016). The terrestrial photogrammetric survey began with the rigorous calibration of the cameras used for the photographic shots to limit the errors induced by the geometric distortions of the lenses and to reduce the processing time of the software used. In order to verify the goodness of the results obtained, three different commercial applications were used: CAgisoft Lens, CEos PhotoModeler and CPix4D Pro Mapper. The convergence of the results of two of them confirmed the validity of the first attempt values that have been to corrected accordingly.

The taking campaign was performed in order to obtain HDR both on the capitals of the columns, and on metal structures that descend from the ceiling - which radiate light to the vaults, the chapels and the nave. A barrier of light that, besides producing strong contrasts between the shaded and the light areas (well beyond the dynamic range allowed by the current sensors of the photographic cameras), has accentuated the glows and the luminous circles around the lighting bodies.

The trouble, known as the starlight effect, has manifested itself in a worrisome way for the photographs of the ceilings and vaults of the chapels, carried out from below with the camera placed in a vertical position.

The use of closed diaphragms and long shutter speeds, imposed by the need to have a high depth of field, has increased the noise. It was not possible to conduct the campaign by turning off the
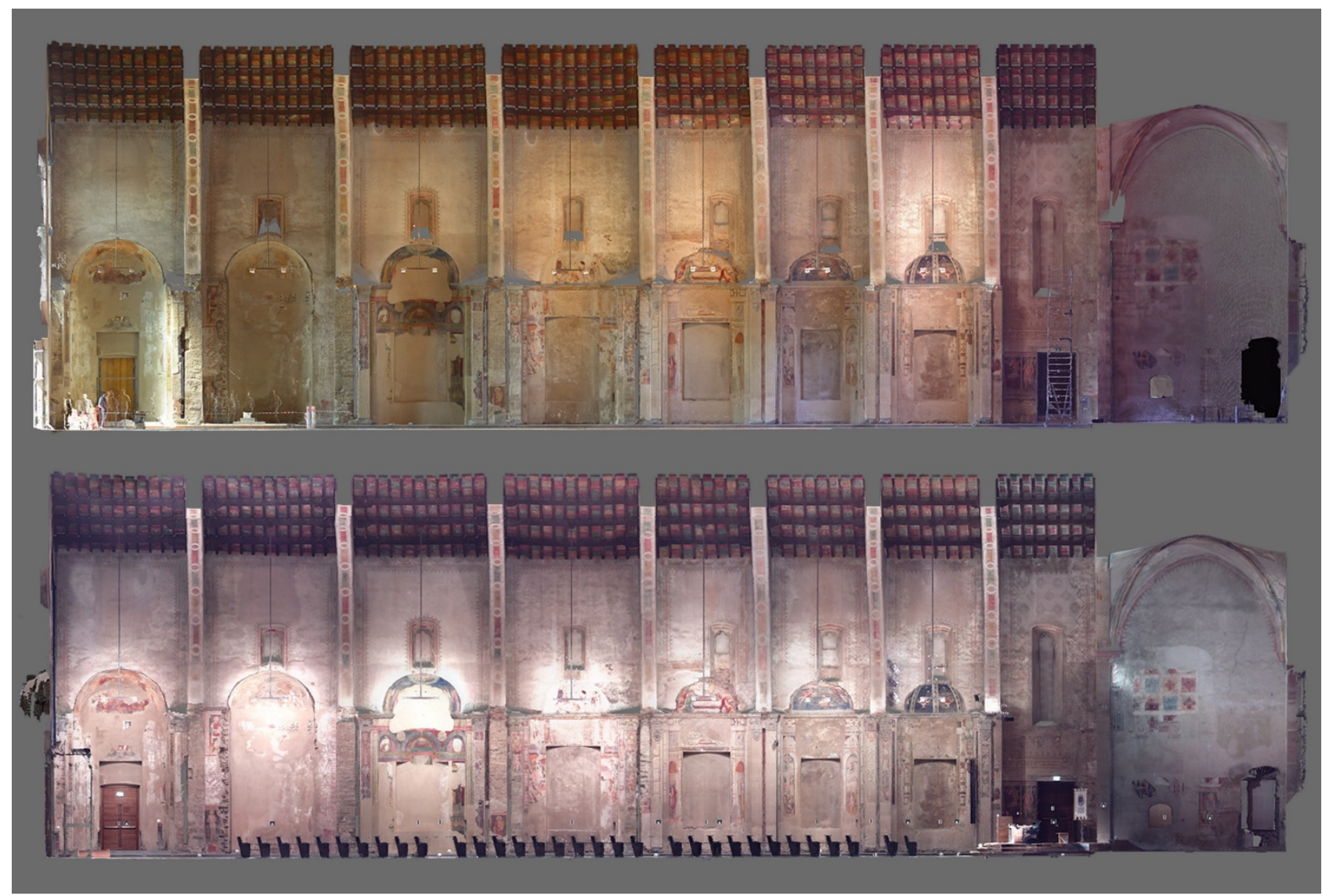

Figure 5. The left side of the nave of the former church of Sant'Agostino during and after restoration works. Comparison between the orthographic projections with the goal of monitoring the degradation evolution (surveys carried out in July 2015 and March 2016).

images from a sequence of multiple shots (the automatic bracketing of the camera used has limited to 3 the number of shots with a deviation of $\pm 1.3 \mathrm{EV}$ ) in order to have greater clarity, both in overexposed and under-exposed areas. A high depth of field was obtained with a shooting mode that favored the closed diaphragms even at the expense of long shutter opening times. A very small Ground Sample Distance (GSD equal to 1.35 $\mathrm{mm} /$ pixel) was obtained with the choice of positioning the cameras at variable distances from the raised surface and using both wide-angle and telephoto lenses. The shots were made whether with the focal plane of the sensor parallel and away from the walls, or tilted 30 and 60 degrees and grazing the walls.

The construction of $3 \mathrm{D}$ models, easy for exteriors, has been difficult for the high areas of the interior, especially the ceiling, due to the artificial lighting system. The church, in fact, is illuminated by LED luminaires positioned at about half height - headlights due to the lack of natural light, compromised by the permanent darkening of the windows on the façade, the only ones that allowed light to enter the church.

The treatment of the images, before their elaboration, performed with appropriate masking actions of the areas affected by the disturbance, reduced the problem but did not eliminate it definitively. The alteration of the light gradient has, in fact, influenced the reconstruction of spatial geometry with an alteration of the position of the points and the creation of artefacts.

The processing carried out by 3D image-based reconstruction digital systems has seen the use of many software, also in order to compare the solutions. Every commercial product has, in fact, some particularities that make it more or less suitable for a given process. In particular, with reference to the mentioned problem, fewer errors have been noted with CPix4D Pro Mapper than with 

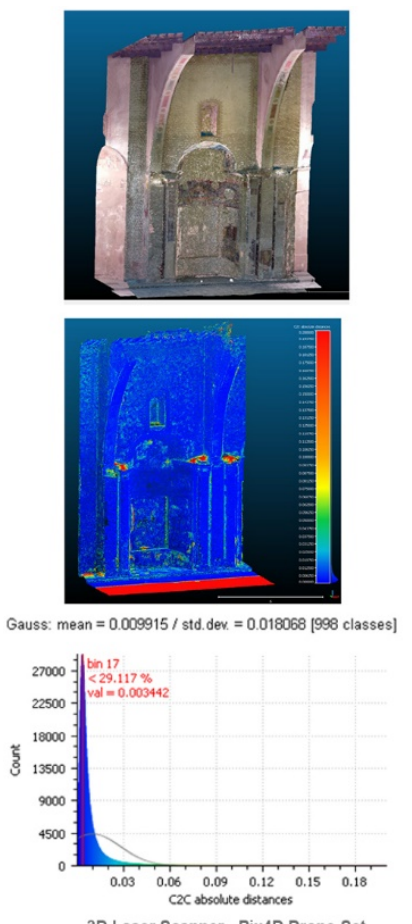

3D Laser Scanner - Pix4D Drone-Set
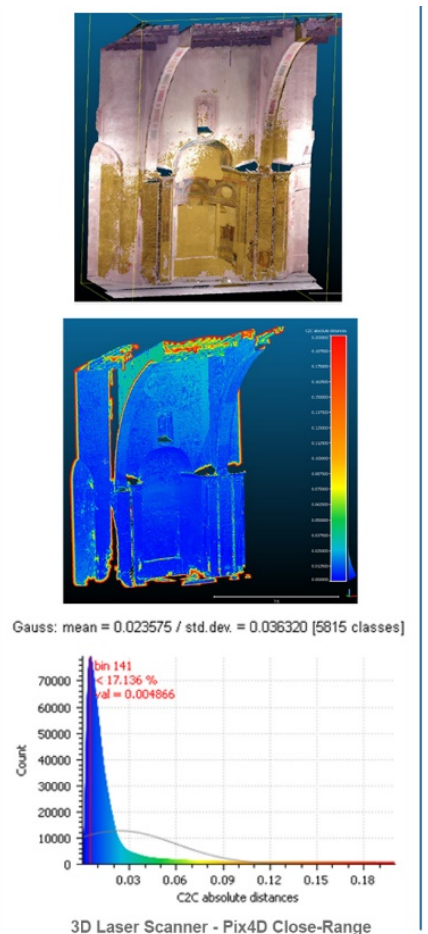

3D Laser Scanner - Pix4D Close-Range
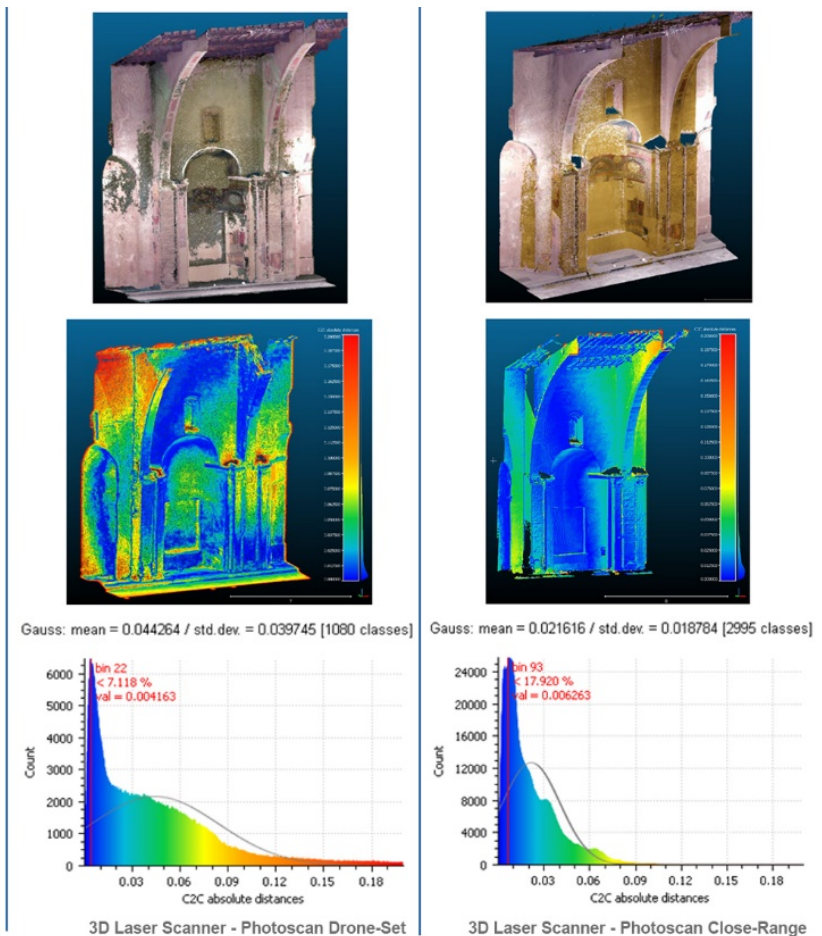

3D Laser Scanner - Photoscan Close-Range

Figure 6. Comparison of different photogrammetric procedures with 3D laser scanning survey.

(C)Agisoft PhotoScan. The first program better retains the geometry of the elements, even in the presence of light disturbances; while the second softens the geometries, supplying the lack of information and rounding the edges with uniform and regular surfaces (figure 6).

It was, therefore, necessary to acquire other sets of images from a height higher than that of the lighting bodies, to integrate the gaps and make the necessary corrections (Nikolakopoulos et al, 2016). The new photographic campaign, not convenient with the use of telescopic poles due to the high heights, was conducted with a small drone equipped with a zenithal top camera that was flown at the level of the arches springers.

\subsection{The aerial photogrammetric survey}

Drones have been used both for acquiring the external aerial images of the Sant'Agostino complex and for obtaining sets of pictures of the intrados of the roof inside the church. The possibility of applying a camera on the back of the drone directed upwards has in fact allowed obtaining images of the arches and of the painted tiles of the ceiling without the defects of enlightenment previously observed. The combined use of the images acquired both by the drone and terrestrial photogrammetry, as well as of 3D laser scanning measurements allowed to obtain a high definition model of the ceiling decorations (figure 7).

Despite having used the same drone - a small quadricopter equipped with an action camera with a high optical quality - the execution of external flights was different from the internal ones (Gabrlik, 2015). The UAV guidance was carried out in manual mode inside the church in order to allow flight a short distance from the ceiling above the lamp system. On the contrary, it was executed in automatic mode in external following the planning of the flight quotas, of the speed on the ground, of the trajectories chosen for the purpose of the best overlap of the images with an average overlap of more than $70 \%$. In automatic mode, 'lift flights' were performed to acquire the images necessary for the reconstruction of the walls (figure 8,9).

The choice to use a small drone, even with lower flight quality than more stable systems such as hexacopters or octocopters and

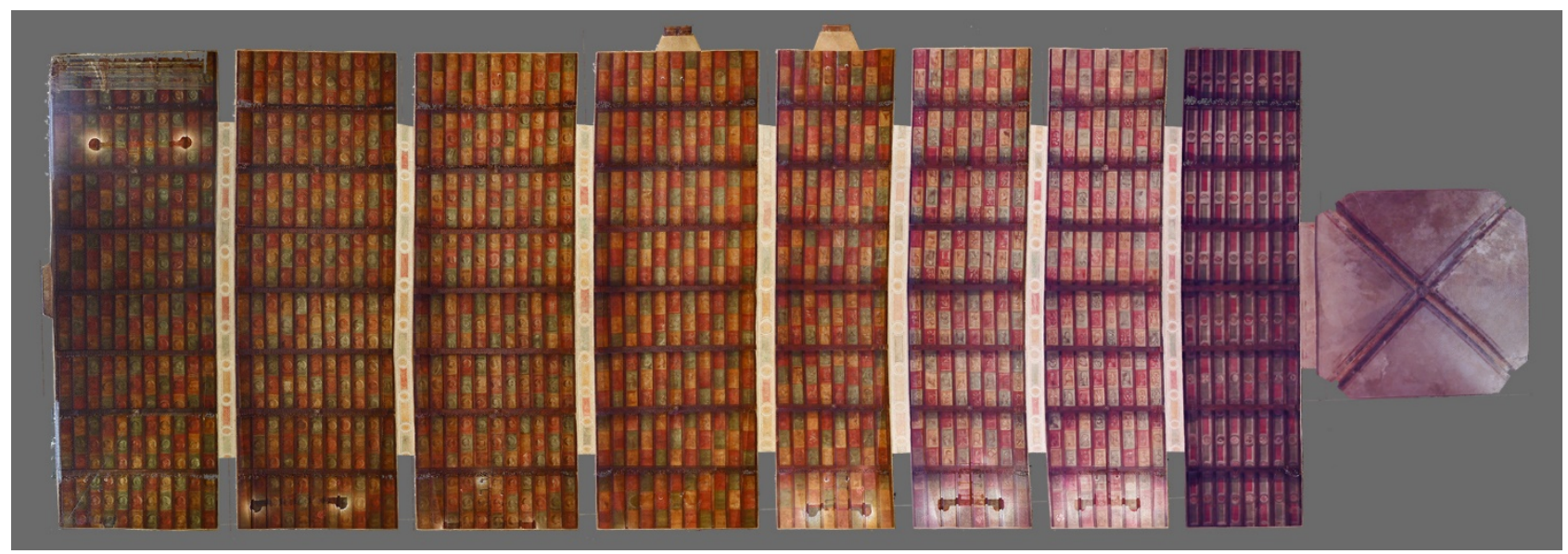

Figure 7. Orthophoto of the ceiling with the painted tiles between the beams and the joints of the roof. Lighting system are still visible. 


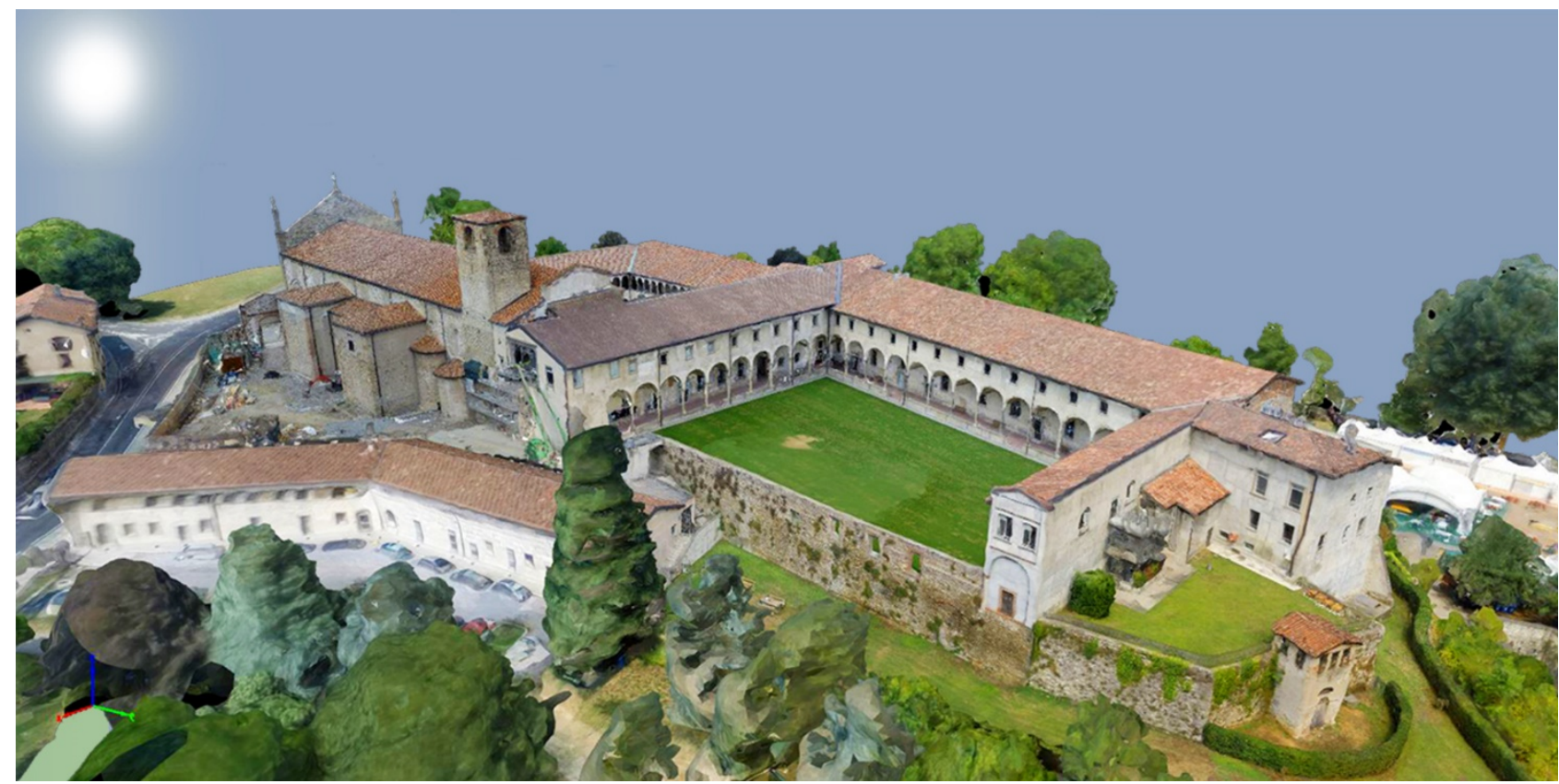

Figure 8. The complex of Sant'Agostino acquired from drone (summer 2015): a bird's eye view of the 3D model.

a tiny medium-quality camera, allowed flying in confined spaces and at small distances from the building, in safe conditions and always with full control of the aircraft.

\subsection{The multimedia data sharing platform}

The former church of Sant'Agostino is a symbolic place for the city of Bergamo and the restoration works have given back the memory of its ancient beauty. The imposing architecture, the frescoes that decorate the chapels and the painted tiles that animate the ceiling narrate the complex stratification of a place rich in history and culture. The wealth and fragility of the monument led to the creation of a multimedia platform for communication and enhancement of the complex that organizes the different types of investigations and the numerous documents collected. Different skills and methods of study converge today in the site, combining in powerful synergy with traditionally distant areas, such as humanities, engineering and information technology (Damiani et al, 2016).

The web portal is divided into two sections: the first diachronic, dedicated to the history of the building based on a specific timeline and including the function assumed by the former church over time, and the second analytic, which examines the architectural and decorative structures considering their state of conservation. Not a simple database for data collection but a relational system in which the different information, separated, can be reorganized through key fields to be interrogated and compared in a different way and dependent on the needs of the operator (Figure 10)

An ongoing project that will continue to be expanded and powered by new studies.

\section{CONCLUSIONS}

The different activities experimented for the survey of the complex of Sant'Agostino produced interesting results, despite the intrinsic difficulties of monitoring a monument during the restoration works in the interior and with very bad and inhomogeneous light conditions. However, this was a great occasion for comparing different approaches, for testing different software and evaluating the results obtained. The combination of laser scanning and terrestrial or aerial photogrammetry has proven to be very effective in order to obtain surveys very reliable for the geometry and in the same time very rich in detail for the monitoring of decay condition of plasters and frescoes. Anyway, the problem of finding the right lighting conditions for an effective photogrammetric reconstruction has still to be solved in a practical way. The obtained $3 \mathrm{D}$ survey can enrich the documentation and observation collected by historians and contribute to lively present this knowledge to a wider public. Moreover, aerial photogrammetry appears to be an effective way to control the geometry of great internal spaces, with high roofs or domes, where observation taken by the floor shown great limitations.

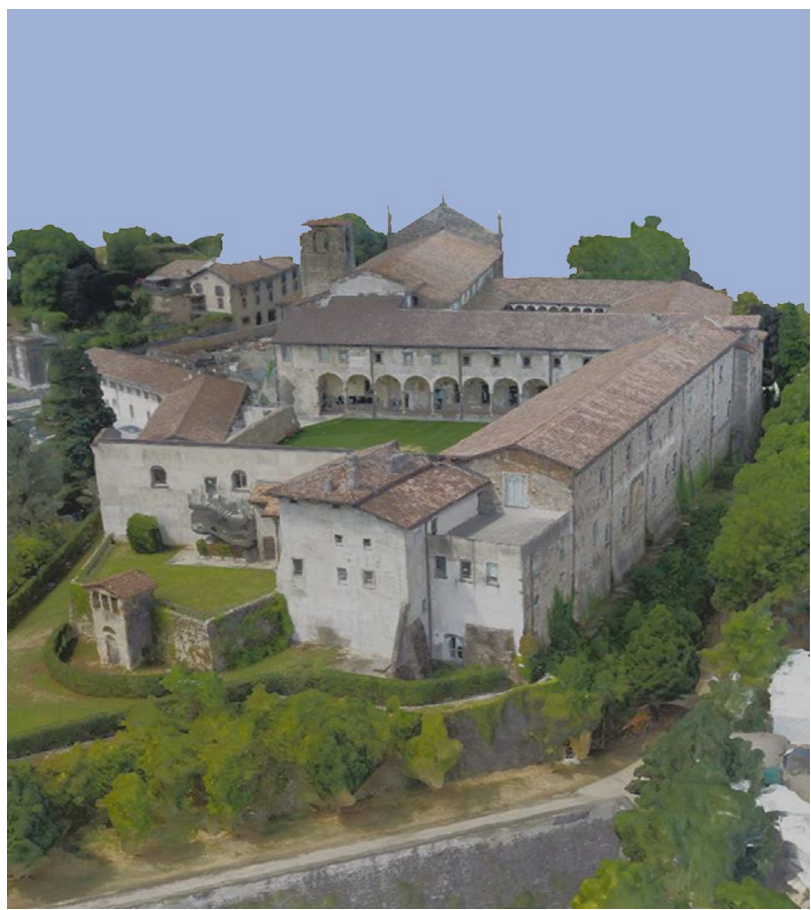

Figure 9. The complex of Sant'Agostino seen from the south. 


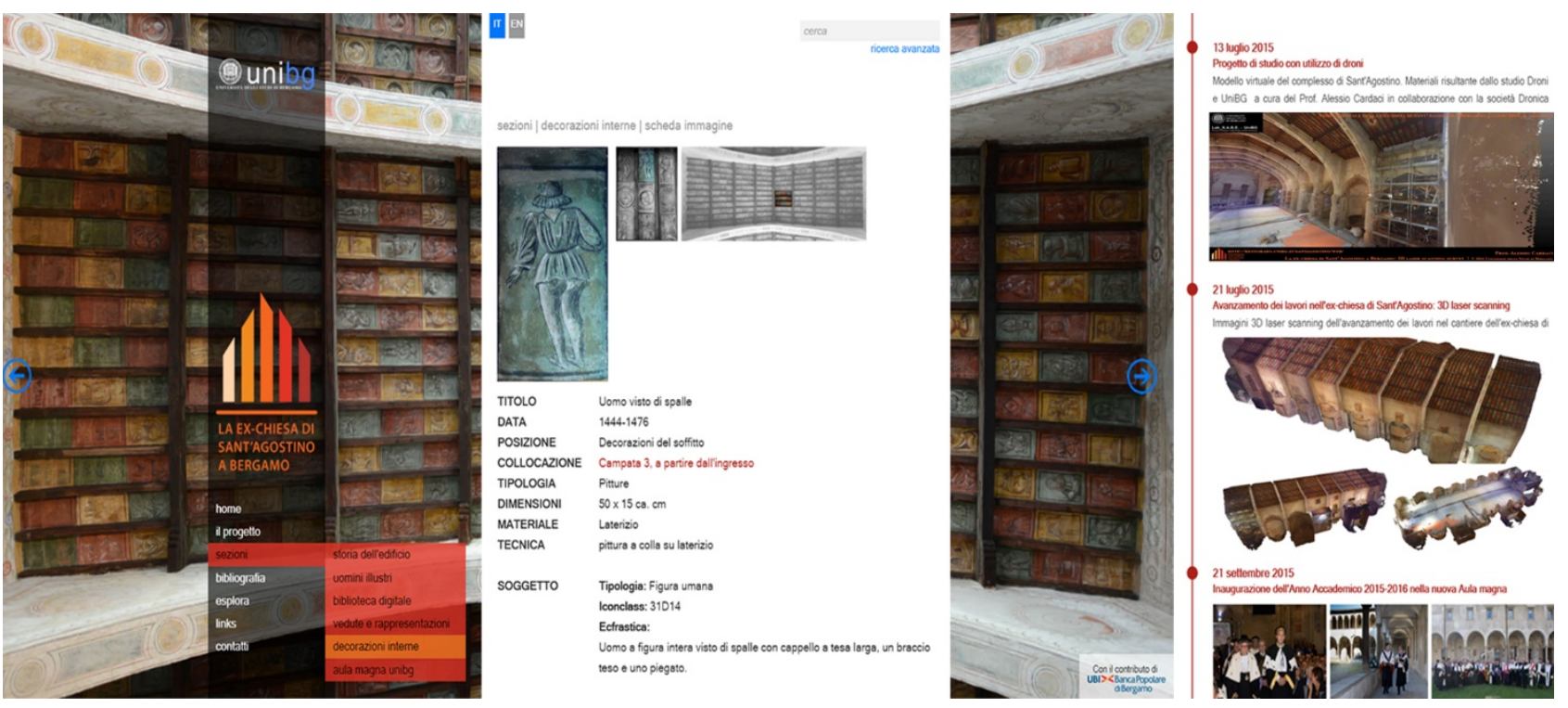

Figure 10. The multimedia data sharing platform and the history of the building based on a specific timeline.

\section{ACKNOWLEDGEMENTS}

The scientific project "La ex-chiesa di Sant'Agostino" was born with the aim of creating a systematic and multidisciplinary study around the monuments of Sant'Agostino di Bergamo. This work is part of a research activity promoted by the University of Bergamo giving rise to a specific data sharing platform (http://rettorato.unibg.it/santagostino/web/); image processing have been carried out in collaboration with the University of Enna, Laboratory for the Restoration of Cultural and Artistic heritage. The authors are thankful to Dronica s.r.l. for the achievement of aerial acquisition campaign with drones.

\section{REFERENCES}

Battini, C., Vecchiattini, R., 2018, Data parametric representation for monitoring of cultural heritage. In Applied Geomatics, May 2018

Bellini, A., 2015. Sant'Agostino - Conservare, fruire. In $L a$ Rivista di Bergamo, N. 84, 12-21.

Bonadei, R., Cappelluzzo, G., Ferlinghetti, R., Frosio Roncalli, L. e Testaverde, A.M. (ed), 2016, Bergamo verso l'Unesco. Terra di San Marco. Da frontiera di pietra a "paesaggi vivi" di pace. Bergamo, Grafica\&Arte.

Bravi, G. O., 2014, Riforma, spiritualità e cultura nel Convento S. Agostino di Bergamo nella seconda metà del Quattrocento. http://www.giuliooraziobravi.it/pdf/ConvSantAgostino.pdf

Colmuto Zanella G. (ed), G., 2011, Territorio e fortificazioni. Bergamo, Edizione Sestante.

Cristini, L. S., 2012, Le mura di Bergamo e la guarnigione veneta fra'500 e'600. Bergamo, Ed Soldiershop.

Damiani, S., Lo Monaco, F., Maffei, S. (2016), La cultura delle immagini: aa chiesa di Sant'Agostino a Bergamo tra l'iconografia sacra e la città. Roma, Aracne Editrice.

Della Torre, S. (ed.), 2003. La conservazione programmata del patrimonio storico architettonico. Linee guida per il piano di manutenzione e il consuntivo, Milano, Edizioni Angelo Guerini e Associati.
Dezzi Bardeschi, M., 2017. Necessità del rilievo per la conoscenza ed il progetto. In Ananke Speciale Geores2017, pp. 4-5.

Gabrlik, P., 2015. The Use of Direct Georeferencing in Aerial Photogrammetry with Micro UAV. In IFAC-PapersOnLine, 48, 380-385.

Mirabella Roberti, G., 2017. The ancient church of St. Augustin as 'Aula Magna' of the University of Bergamo. In ConservationAdaptation, EAAE Transaction on Architectural Education N. 65, pp. 191-200.

Musso, S. F., 2017. Rilevare/Restaurare: una diade inscindibile. In Ananke Speciale Geores2017, pp. 24-29.

Nikolakopoulos, K., Soura, K., Koukouvelas, I. and Argyropoulos, N., 2016. UAV vs. classical aerial photogrammetry for archaeological studies. Journal of Archaeological Science: Reports 14, 758-773.

Pepe, M., Ackermann, S., Fregonese, L., Achille, C., 2016. 3D Point cloud model color adjustment by combining terrestrial laser scanner and close range photogrammetry datasets. In $I C D H$ 2016: 18th International Conference on Digital Heritage (Vol. 10, pp. 1942-1948). International Journal of Computer and Information Engineering.

Petrò G., 2011, Le trasformazioni della chiesa e del convento di S. Agostino tra il XV e il XVI secolo: il ruolo delle famiglie bergamasche. In Mencaroni Zoppetti M., Gennaro E., Società, cultura, luoghi al tempo di Ambrogio da Calepio. Bergamo, Edizione Sestante, pp. 103-178.

Schiavini Trezzi, J. (ed), 2007, Il Convento di Sant'Agostino. Storia e significati di un monumento, Bergamo, Edizione Sestante

Zanella V. (ed), 1990, Le mura di Bergamo: 1588 - 1988. Atti dell'Ateneo di Scienze. In Lettere ed Arti di Bergamo, vol. 49. Bergamo: Edizioni dell'Ateneo. 